American J. of Engineering and Applied Sciences 2 (1): 202-211, 2009

ISSN 1941-7020

(C) 2009 Science Publications

\title{
Supply Chain Performance Evaluation: Trends and Challenges
}

\author{
${ }^{1}$ Ezutah Udoncy Olugu and ${ }^{2}$ Kuan Yew Wong \\ Department of Manufacturing and Industrial Engineering, Faculty of Mechanical Engineering, \\ University Technology Malaysia, 81310 UTM Skudai, Malaysia
}

\begin{abstract}
Problem statement: In today's manufacturing world, globalization policies and rejuvenation have created a more intensive competition amongst manufacturers. On the other hand, manufacturers have turned to the option of adopting innovative technologies, process re-engineering and strategies such as efficient supply chain management to achieve a sustainable competitive advantage. Effective supply chain performance measurement has been identified as a key issue towards efficient supply chain management. To explore the extent of research in supply chain performance measurement and establish the gap in knowledge in supply chain performance measurement using fuzzy logic operation. Approach: Literatures in the area of supply chain performance measurement had been extensively reviewed. Both traditional and fuzzy logic approaches to supply chain performance measurement were scrutinized. Further scrutiny was carried out to establish potential research areas in the application of fuzzy logic operations in supply chain performance measurement. Results: The supply chain performance measurement using fuzzy logic operation was identified as a new direction in measuring the uncertainty and ambiguity surrounding supply chain performance measurement. Direction for further studies in the application of fuzzy logic operation in supply chain management and its performance measurement were also identified. Conclusion: Result of this study implied that there is still a gap in knowledge in the area of supply chain performance measurement. This new direction of studies involved extending the existing supply chains to incorporate product recovery after the useful life.
\end{abstract}

Key words: Supply chain, supply chain performance measurement, supply chain management, fuzzy logic

\section{INTRODUCTION}

Supply chain management concept originated from the recognition that the process of transforming raw materials into final products and delivering those products to customers is becoming increasingly complex. On that note, it has become increasingly apparent that analysis as well as the subsequent improvement of the individual supply chain echelons does not lead to improvement of the supply chain as a whole. Therefore, the concept of the supply chain emerged to describe all production stages from raw material procurement to final product delivery to the end user $^{[1,2]}$. Competition in the manufacturing environment has shifted from individual firms to their respective supply chains, therefore only a firm with agile and versatile supply chain can sustain the effective competitive edge ${ }^{[2-7]}$. With product demands being more customer-driven, shrinking product lifecycles and alternative products springing up by the hour, there is thus a need for an effective management of the supply chain rather than just the internal factors ${ }^{[2]}$. For an effective and credible management of the customer, a joint effort of the suppliers, manufacturers and distributors is required ${ }^{[5]}$. As supply chain focuses on the processes management within and beyond organizational boundaries, thus a measure of its performance is necessary for its effective operation and control. This study looks at the various studies on supply chain performance measurement and points out their achievements as well as their limitations. Sequel to the limitations highlighted in the review, new directions for future studies are proposed.

Supply chain: Supply Chain comprises a worldwide network of suppliers, factories, warehouses, distribution centers and retailers through which raw materials are acquired, transformed and delivered to the end user ${ }^{[5]}$. Supply chain is a combined system which comprises planning, sourcing, making and development of

Corresponding Author: Olugu Ezutah Udoncy, Department of Manufacturing and Industrial Engineering,

Faculty of Mechanical Engineering, University of Technology Malaysia, 81310 UTM Skudai, Malaysia 
processes with its constituent parts to include material suppliers, production facilities, distribution centers and customers linked together through the feed forward flow of material as well as feedback flow of information ${ }^{[9,10]}$. Hult et al. ${ }^{[11]}$ described supply chain as value-adding relationship between partially discrete, yet interdependent entities that cooperatively procure and transform raw materials into finished products through sequential network structures. According to Beamon ${ }^{[2]}$ supply chain is an integrated process which involves the processing of raw materials into finished goods and making them available to the end user. Chan et al. ${ }^{[4]}$ described supply chain as the partnership and/or alliance involving suppliers, downstream customers and a host of logistics service providers to exploit their capabilities in order to create value for the end consumer. The definition of supply chain is not exhaustive since supply chain concept has a lot of implications to different practitioners depending on where they are coming from. Primarily, this chain is made up of four basic echelons including, the suppliers, manufacturers, distributors and end users. These echelons are characterized by different constituent facilities, thus making the chain a complex network. Sabri and Beamon ${ }^{[1]}$ stated that following the nature of the chain, any factor which affects any particular element in the chain will be extended to the rest of the chain. Vonderembse et al. ${ }^{[3]}$ classified supply chain into three different categories which are lean supply chain, agile supply chain and a hybrid supply chain which is a combination of the two. $\mathrm{Xu}$ et al.$^{[12]}$ supported this by asserting that four different supply chain strategies have been adopted by different companies in different times to compete in a given market and these are lean supply chain, agile supply chain, legible supply chain, adaptive supply chain. Lean supply chain was described as the type of supply chain which employs continuous improvement approach ${ }^{[3]}$. It was further expounded that these efforts are geared towards the elimination of waste and non-value adding processes within the chain, thus leading to internal manufacturing efficiencies and set up reduction ${ }^{[3,12]}$. This type of supply chain lacks considerable responsiveness to external requirements such as customer needs. On the other hand, agile supply chain was described as a supply chain with focus on direct interface between the companies and markets, involving external perspective on flexibility and responsiveness ${ }^{[3]}$. This was further explained as taking a customer oriented approach by adopting flexibility and dynamism across organizations. The hybrid is a combination of agile and lean supply chains. Efficiency and effectiveness of a supply chain irrespective of the type lies in effectiveness of its management.
Supply chain management: Based on definition by Wong and Wong ${ }^{[10]}$, supply chain management is a set of approaches utilized to efficiently integrate suppliers, manufacturers, warehouses and stores so as to produce and distribute products and services to the customers at the right quantities, right locations at the right time, minimizing the system wide cost while satisfying the service level requirements. Supply chain management according to ${ }^{[9]}$ and Vonderembse et al. ${ }^{[3]}$ involves the systematic, strategic as well as operational decision making which are put in place for an effective and efficient supply-chain performance. Mentzer et al. ${ }^{[6]}$ and Chan et al. ${ }^{[4]}$ defines supply chain management as a systematic, strategic coordination of the traditional business functions within a particular organization and across businesses within the supply chain for the purpose of enhancing long term organizational performance and the overall supply chain. Supply chain management is the most advanced state in the development of evolutionary purchasing and procurement and other supply chain activities. Hervani et al. ${ }^{[13]}$ further highlighted that supply chain management involves the coordination and management of a complex network of activities involved in the development of finished product to the end user or customer. Supply chain management has been described as an integrator amongst suppliers, suppliers' suppliers, manufacturers, distributors and customers which uses certain tools such as information technology to actualize customer expectation ${ }^{[3,14,15]}$. Thus, it can be described as a process which involves sourcing raw materials and parts, manufacturing and assembling products, storage, order entry and tracking, distribution of goods using different channels and final to the end user. This can be described in other words as the management process that deals with inbound and outbound logistics flows, from focal organizational point of view, involving its suppliers and customers. The competition has also moved from the ability of individual firms to the robustness of their supply chain. Although supply chain management is a relatively new and rapidly expanding field, it is transforming the pattern in which manufacturing and non-manufacturing operations sought customers' needs ${ }^{[16]}$. Therefore, supply chain management involves the coordination of supply chain function in order to achieve optimum performance. Implementation of Supply Chain management is a long drawn process which requires both restructuring of internal organizational activities and a proper investigation and analysis of the relationship existing between the manufacturer and the suppliers, distributors and others involved in the value creation process. 
The manufacturing environment is characterized by unlimited dynamics which makes this process very demanding, thus the supply-chain management system should be able to coordinate the revision and improvement of plans and/or schedules across supplychain functions. For an effective implementation of supply chain management, all parties involved must be taken into account, such as the suppliers, suppliers' suppliers, various functions within the manufacturing organization, distributors, retailers and every party whose contribution can aid in the promotion of a the organization's market share. It has been pointed out that, for an effective and credible management of the customer, there is need for joint effort of the suppliers, manufacturer and distributors ${ }^{[17]}$. According to Lai et $a l .{ }^{[17]}$ and Mentzer et $a l .{ }^{[6]}$, effective supply chain management increases organizational effectiveness and leads to improved customer value, better resources utilization and improved revenue. Liang et al. ${ }^{[18]}$ highlighted that for an effective supply chain management; there is need for overall performance evaluation of the entire SC, therefore a combination of resources of the chain members in the most efficient way so as to generate competitive as well as cost effective products and services.

\section{MATERIALS AND METHODS}

The materials and procedure applied in this study involved the use of books and journal articles containing researches in supply chain management and supply chain performance measurement. Special emphasis was placed on the application of fuzzy logic in supply chain performance measurement. This is because fuzzy logic operation has a lot of benefits which are reflected in the fuzzy aspect of this study. The journal articles were searched with different search engines through the most popular electronic journal holding organizations on the internet. The search involved searching for supply chain performance measurement. The next stage involved searching with the same phrase with the affixing of fuzzy logic. This also brought some result which forms the part of the sources. These results were sieved for relevance to the topic under consideration to ascertain their viability and relevance. The selected literatures were then reviewed in-depth to reveal the content which forms a considerable part of this work. The next thing was to understand the perception of different researchers about performance measurement. From there, it was extended to incorporate performance measurement in supply chain context.
Supply Chain Performance Measurement (SCPM): Performance measurement according to Bhagwat and Sharma ${ }^{[19]}$ describes the feedback on operations which are geared towards customer satisfaction and strategic decisions and objectives. They further pointed out that performance measurement reflects the need for improvement in operational areas which are found wanton in performance measures. Neely ${ }^{[20]}$ described performance measurement as the process of quantifying the efficiency and effectiveness of actions. Based on Neely et al. ${ }^{[21]}$ assertions, when you can measure something and express it in numbers, you have good background knowledge about it; otherwise your knowledge about it is meager and unsatisfactory. Kaplan and Norton ${ }^{[22]}$ supported this by their exertion that what you measure is what you get. Gunasekeran et al. ${ }^{[23]}$ identified effective performance measurement as necessary in supply chain management. Bond ${ }^{[24]}$ went ahead to identify performance measurement as having the benefits of stabilizing the process and identifying areas for further improvement within the system. He further stated that measurement of performance will also reveal whether there is need for an organization's continuation in its current method (maintaining the status quo) or adopting a re-engineering of its system to affect the areas which are found deficient. Lai et al. ${ }^{[1]}$ exerted that lack of adequate performance measurement has been identified as one of the major obstacles to efficient supply chain management. It is an established fact that in order to improve supply chain effectiveness and realize a smooth flow of resources within it, there is a need to measure its performance $\mathrm{e}^{[9,10]}$.

Traditional approaches to SCPM: Many attempts have been made on supply chain performance measurement using conventional approaches. Some of these approaches are reviewed here under.

The supply chain operation reference model was proposed by supply chain council in 1996 as a framework which integrates the basic concepts of business process re-engineering, bench marking and process measurement into a cross-functional framework $^{[25]}$. Sabri and Beamon ${ }^{[1]}$ used a performance vector to integrate strategic and operational analysis of supply chain in order to describe the efficiency and effectiveness within the supply chain. Wong and Wong $^{[10]}$ provided a frame work with which to study supply chain performances by developing a Data Envelopment Analysis (DEA) model for the internal supply chain performance efficiency using case study applications. Chen et al. ${ }^{[26]}$ investigated the efficiency existing between two supply chain members and established the existence of equilibrium efficiency plans 
for both supplier and the manufacturer regarding their efficiency functions. Liang et al. ${ }^{[18]}$ developed a several DEA-based approach suitable for measurement of supply chain efficiency when intermediate measures are built in into the evaluation scheme. Chen et al. ${ }^{[26]}$, proposed several DEA-based supply chain efficiency functions aimed at identifying the inefficiency within the chain members by developing two efficiency functions for the manufacturer and the supplier. They were able to identify that there exist several Nashequilibrium in the supplier-manufacturer game and the bargaining model can be used to determine a unique sub-game perfect Nash equilibrium in existence. Lai et al. ${ }^{[17]}$ developed a measurement model and a measurement instrument with an established measure for supply chain performance in transport logistics based on a SCOR model. They came up with a SCP measurement instrument which reflected the effectiveness of service for the shippers, operation efficiency for transport logistics service providers and finally service effectiveness for consignees. Liang et al. ${ }^{[18]}$, developed new DEA-based models which were aimed at correctly characterizing a multi-member supply chain operation and at the same time to calculate the efficiencies of the supply chain operations and its members. This was aimed at correcting and making up for the inadequacies of convectional DEA model at evaluating multi-member supply chain operations directly. This model was also believed to be extensible to multi-stage production systems. Baramichai ${ }^{[27]}$ proposed a tool called the Agile Supply Chain Transformation Matrix (ASCTM) and the implementation methodology for a systematic approach to achieve agility in the supplier-buyer supply chain, thus helping companies create and improve their agility by relating the business changes with the appropriate approaches for supplier-buyer supply chain configuration and supplier-buyer relationship establishment and determining the business processes and the infrastructures needed to support the creation of agile capability.

Berrah and Cliville ${ }^{[28]}$ developed a frame work which links elementary performance expression to the over all performance in a supply chain. Aggregation was done using Choquet integral operator. Their frame work allows comparison of situations conventionally considered as "incomparable". Zheng and Lai $^{[29]}$ proposed a supply chain performance evaluation system which uses a quantified indicator system to measure and evaluate the performance in an agile virtual enterprise. This is an improvement on the traditional Balanced Score Card by extending it into five dimensions based on the Rough Set theory. Chow et al. ${ }^{[30]}$ examined the definition and measurement of performance in logistics studies by examining the various ways in which "performance" has been defined. Data collection methods, sources and the measures that have been used were identified and potential sources of performance data were identified.

Most of these approaches have, to a great extent contributed in performance measurement of a supply chain, but there are still rooms for improvement as highlighted in the ensuing lines. As pointed out by ${ }^{[20]}$, they are inflexible and lack continual improvement. It was further pointed out that complexities in supply chain management have made these techniques cumbersome when dealing with a large amount of data $^{[31]}$. In addition, their inability to handle ambiguity, stochasticity and inconciseness inherent in supply chain performance measurement renders them appropriate to a certain limitation $^{[31,32]}$. These deficiencies have led to the application of a more robust and computational capable approach in the form of fuzzy operations in the measurement of supply chain performance ${ }^{[31,32]}$.

Fuzzy Logic (FL): Fuzzy logic originates from fuzzy set theory which was proposed by $\mathrm{Zadeh}^{[33]}$ and has since found a number of applications as a theory of graded concepts. It provides a mathematical framework where vague, conceptual phenomena can be rigorously studied $^{[34]}$. Fuzzy logic models human experiential knowledge in any domain. When applied to solve performance measurement or prediction problems, fuzzy logic takes the help of the knowledge from the domain expert and employs fuzzy arithmetic to produce fuzzy inference systems. Fuzzy logic is an application of the fuzzy set theory particularly used in dealing with process imprecise information with a changed membership function ${ }^{[35]}$. Fuzzy operation is a process of 'crisp-fuzzy-crisp' for a real system in which the original input and the terminal output must be crisp variables, but the intermediate process is a fuzzy inference process ${ }^{[36]}$. Fuzzy inference is a method that interprets the values in the input vector and assigns values to the output by means of some set of fuzzy rules. In a classical set, an element either belongs to or does not belong to a set. Since fuzzy sets describe vague concepts based on the premise that the elements used are not numbers but belong to words or the value of a linguistic variable, an element of a fuzzy set naturally belongs to the set with membership values from the interval $[0,1]$. The shape of the membership function of fuzzy sets can be either linear (trapezoidal or triangular) or various forms of non-linear, depending on the nature of the system being studied. To implement fuzzy logic technique to a real application requires the following methodology (Fig. 1). 
Am. J. Engg. \& Applied Sci., 2 (1): 202-211, 2009

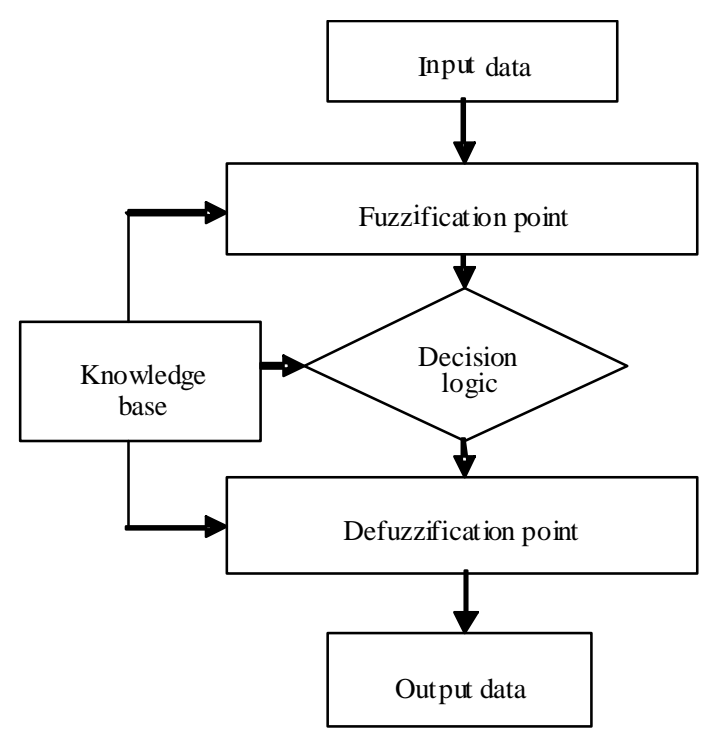

Fig. 1: Methodology for fuzzy logic application

From Figure 1, it can be seen that in fuzzy logic operation, the output of a fuzzy process is derived from fuzzifications of inputs using the associated Membership Functions (MFs). Thus, the output of a fuzzy logic system is based on different membership functions, which can be considered as a range of inputs. The first step involves fuzzification which implies the conversion of classical data or crisp data into fuzzy data or membership functions. This information is then fed to the decision logic or fuzzy inference process which combines membership functions with the control rules to derive the fuzzy output. The next step involves the defuzzification process which converts a fuzzy output into a non-fuzzy one by using different methods to calculate each associated output. Finally, the knowledge base system comprises experts' knowledge of the application domain as well as the decision rules which depict the relationship between the inputs and outputs.

Fuzzy logic's primary aim is to provide a formal, computationally-oriented system of concepts and techniques for dealing with modes of reasoning which are approximate rather than exact ${ }^{[37]}$. Thus, in fuzzy logic, exact (crisp) reasoning is considered to be the limiting case of approximate reasoning. According to Jain et $a l .{ }^{[37]}$, the primary goal of fuzzy systems is to formulate a theoretical foundation for reasoning about imprecise propositions, which is termed approximate reasoning in fuzzy logic technological systems.

According to Alex ${ }^{[32]}$ and, Kumar and Ravi ${ }^{[34]}$, fuzzy logic incorporates a simple 'IF X and Y, then Z' approach in solving problems rather than using a systematic mathematical model, thus fuzzy logic is used to mimic normal human reasoning but in a rather faster way. Fuzzy logic is an empirical based model which relies on the experience of the operator and provides a simple way to arrive at a definite conclusion based upon vague, ambiguous, imprecise or missing input information ${ }^{[32]}$. Although the approaches in fuzzy logic are quite descriptive, they are capable of mimicking normal human reasoning at a very high rate ${ }^{[5,31,32]}$. It is very robust and forgiving of operator's data input and often works when first implemented with little or no tuning. It is inherently robust as it doesn't require precise data inputs and the output and/or feedback is a smooth function despite a wide range of input variation $^{[5]}$. The application of fuzzy is not limited to a few feedback inputs and one or two outputs and neither is it necessary to measure or compute the rate of change of parameters in order for it to be implemented ${ }^{[9,31,32]}$. Based on the rule-based operation any reasonable number of inputs can be processed (1-8 or more) and numerous outputs (1-4 or more) can be generated. The use of fuzzy logic can be applied to measuring the performance of non-linear systems which would be difficult or impossible to model mathematically.

\section{RESULTS}

The findings of the extensive review on the performance measurement of supply chain are detailed in the ensuing paragraphs. The findings encompass fuzzy applications in supply chain management and the strengths of the research which adopted it.

Using fuzzy logic in SCM: A fuzzy set is one in which the constituting elements belong to a set with some degrees of membership $\mu$. Thus, in a more general term, a fuzzy set $\mathrm{F}$ inside a universe of discourse has a membership function $\mu_{\mathrm{F}}$, whose values fall within the interval [0-1], that is $\mu_{\mathrm{F}}$ : $\mathrm{U}[0,1]$. Therefore the fuzzy set $\mathrm{F}$ in $\mathrm{U}$ can be presented as $\mathrm{F}=\left\{\left(\mathrm{u}, \mu_{\mathrm{F}}(\mathrm{u})\right), \mathrm{u} \varepsilon \mathrm{U}\right\}$ which comprises a set of ordered pairs of a generic element $u$ and its degree of membership functions. The probability that $\mathrm{u}$ is a member of $\mathrm{F}$ is the membership function $\mu_{\mathrm{F}}(\mathrm{u})$. More details on the fuzzy operation can be obtained in $\operatorname{Zadeh}^{[33]}$ and Ganesh ${ }^{[38]}$. The membership function of the union of two fuzzy sets A and $\mathrm{B}$ is defined as the maximum of the two individual membership functions, while the membership function of the intersection of two fuzzy sets A and B is defined as the minimum of the two individual membership functions. This is called the minimum criterion. Fuzzy union and intersection are represented by the following equations respectively: 
A $U B=\left\{x, \max \left(\mu_{A}(x), \mu_{B}(x)\right) / x\right.$ is an element of $\left.U\right\}$

A n $B=\left\{x, \min \left(\mu_{A}(x), \mu_{B}(x)\right) / x\right.$ is an element of $\left.U\right\}$

With respect to supply chain performance measurement, the procedure for the application of fuzzy logic operation in this arena can be shown in Fig. 2. Firstly, the performance measures are identified and measured together with their respective priority factors (weighting factors). Some examples of performance measures include customer satisfaction, delivery time, cost, flexibility and quality. The weighting factors are developed by managers and other experts based on their effects on the supply chain performance.

In Fig. 2, it can be seen how fuzzy logic can be applied in the measurement of performance of a supply chain. The measures are obtained using linguistic terms such as poor, fair, good and excellent which are introduced into the Fuzzy Decision Making System (FDMS) as inputs. The FDMS is trained using expert knowledge. The output is a description of the attribute such as excellent, good, normal or poor. Finally, defuzzification method e.g., Mean of Maximum is used to transform the fuzzy assessment results into a single numerical value so that it could be computed together with quantitative metrics results to calculate the overall score. With the FDMS, all the measure can be effectively evaluated.

The next step involves the development of a fuzzy subset and membership functions for every input and output variable for the supply chain performance measurement using experts' knowledge. Following this, the same expert knowledge is applied in developing a set of 'if then' rules which forms the basis of the relationship between the input and output variables. The input values are then related to their fuzzy set using decision rules. Finally, a fuzzy result for the output is obtained which is then defuzzified to obtain a value for the output.

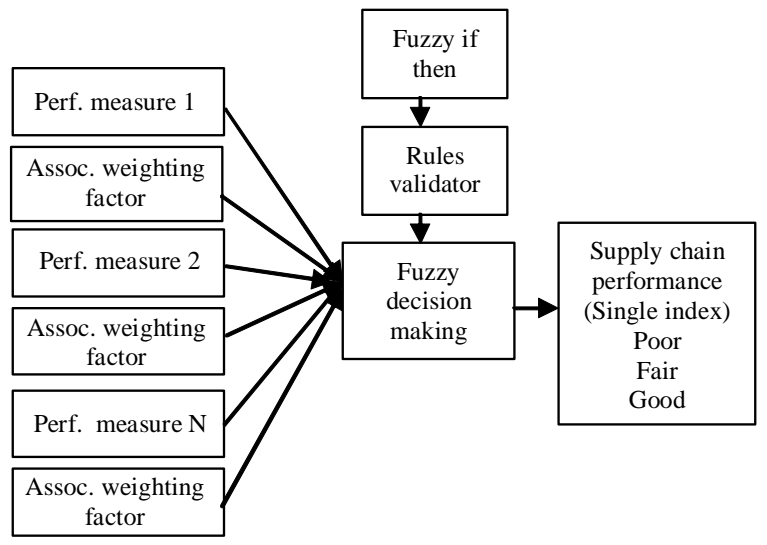

Fig. 2: Illustration of SCPM with FL
Current studies in SCPM using fuzzy logic: Fuzzy logic technique has been applied by many researchers to measure supply chain performance. Such applications include the study by ${ }^{[4]}$ involving an innovative performance measurement system for supply chain performance improvement using fuzzy set theory. Based on the work done by Alex ${ }^{[32]}$, fuzzy point estimation has been used to provide a new approach in modeling the uncertainties involved in supply chain management. A four-aspect performance measure which involved a simplified supply chain model, a cross organizational performance measurement using the fuzzy set theory and weighted average method was proposed by ${ }^{[8]}$. On the same note, Yeh et al. ${ }^{[39]}$ used a Six Sigma DMAIC process based framework to develop a modified two-tuple fuzzy logic control model to evaluate the performance of SCM. Another work was conducted by Zheng and Lai ${ }^{[40]}$ in which an integrative supply chain performance measurement which incorporated the extension of the dimension of the traditional Balanced Scorecard was adopted. The decision rule set of performance measurement prediction was obtained using attribute reduct and value reduct of decision table. Based on the work carried out by Kanda and Deshmukh ${ }^{[41]}$, a fuzzy logic approach combined with the AHP was applied in the evaluation of the level of coordination amongst the supply chain members. Other works using fuzzy logic operation include the one by Rajkumar and Kumar ${ }^{[42]}$, in which an evolutionary genetic algorithm-based fuzzy methodology for the evaluation of suppliers' performance was developed to evolve the optimal set of fuzzy rule base. Others include, Chan and $\mathrm{Qi}^{[31]}$ who proposed an innovative channel-spanning performance measurement method from a system perspective using fuzzy set theory. Chan and $\mathrm{Qi}^{\left[{ }^{[8]}\right.}$ applied a fuzzy set theory in performance measurement by adopting a process-based perspective by building a model which holistically measure performance of complex supply chains. Chan et al. ${ }^{[4]}$ developed a fuzzy decision model for integrated performance measurement using integrated information system for providing performance and fuzzy decision model was applied to determine the improvement action. Lazarevic and Wong $^{[44]}$ proposed a methodology for monitoring and controlling service quality level using applied fuzzy control model. Lin et al. ${ }^{[5]}$ used a performance rating and importance weight of different agility capabilities assessed by experts to express linguistic terms and appropriate fuzzy numbers were used to present the linguistic values with the application of a sample fuzzy arithmetic operation to synthesis the fuzzy numbers into one fuzzy number which was used to access the agility 
index of a manufacturing operations. A Fuzzy Performance Importance Index (FPII) of each agility capability was devised to identify the adverse factors which indicate negative flow of events. $\mathrm{Xu}$ et al. ${ }^{[12]}$ proposed a supply chain performance measurement system using AHP and fuzzy logic which was applied to integrate both qualitative and quantitative metrics to provide a complete view of the supply chain management and its overall competitiveness.

Strengths of current studies using FL: Based on the merits of fuzzy logic as a tool, the studies which focused on its applications in supply chain performance measurement have a lot of accruable advantages compared to studies which focused on traditional methods. Firstly, Alex ${ }^{[32]}$ and Zheng and Lai ${ }^{[29]}$ have demonstrated that fuzzy logic operation can provide a new approach in the modeling of the uncertainties which characterize supply chain management. Secondly, the application of fuzzy logic operation in supply chain performance measurement is easier to perform and more accommodating compared to the conventional approaches, especially when the number of operated input data is large. In spite of the fact that Chan and $\mathrm{Qi}^{[8]}$ and Chan et $\mathrm{al}^{[4]}$ applied the fuzzy theory and weighted average technique, they also demonstrated a holistic approach involving the cross boundary system perspective and process-based method spanning through a whole supply chain. Chan and $\mathrm{Qi}^{\left[{ }^{[8]}\right.}$ extended the application of fuzzy logic to encompass tangible and non-tangible performance measures in multiple dimensions with a cross organization performance evaluation. An integrative supply chain performance measurement using fuzzy logic approach was demonstrated by ${ }^{[40]}$. Finally, Kanda and Desmuhk ${ }^{[41]}$ have established the coordinating ability in the application of fuzzy logic in supply chain performance measurement.

\section{DISCUSSION}

Most of the current studies on supply chain performance measurement have yet to use the abundant benefits of fuzzy logic operation such as the approximate reasoning technique in deducing the performance of a close loop chain. As green supply chain incorporates a new dimension of value into the traditional supply chain, namely, environment ${ }^{[45]}$, the primary material flow which starts from raw material supplier and ends at consumer has been extended to cover a 'from birth to graveyard' perspective ${ }^{[45]}$. This implies that eventually, materials need to be sent back to the supplier for recycling and reprocessing purposes.
Global supply chain management practices have increasingly focused on integrating supply chains which encompass suppliers, manufacturers, distributors, customers and reverse logistics, hence the term "close loop" "46]. A lot of authors have highlighted the need for greening the supply chain to include regulatory, marketing and competitive reasons ${ }^{[13,47,48]}$. Hoek ${ }^{[49]}$, stated that supply chain greening can be resource saving in the form of waste reduction and productivity improvement. Rao and Holt ${ }^{[50]}$ elucidated that green supply chain management promotes efficiency and synergy amongst organizations. Others see it as a strategy to provide the necessary information which are required in the fulfillment of the limitations that are posed by environmental legislation and various regulations ${ }^{[2,13,48,50]}$.

However, to date, there is a lack of consideration with in-depth study which focuses on the performance measurement of this type of supply chain.

As corporations attempt to move towards environmental sustainability, managers must extend their efforts to improve environmental practices across their supply chain ${ }^{[51]}$. The literature characterizing environmental management within the supply chain has been slowly building, but remains sparse ${ }^{[51]}$. Thus, there is a need to extend the supply chain performance measurement using fuzzy logic approach to a close loop chain, which is a green supply chain that integrates suppliers, manufacturers, distributors, customers and reverse logistics ${ }^{[46]}$. Based on such performance measurement system, it will be necessary to deduce the relationship between greening of the supply chain and the traditional performance measures such as cost, delivery time, throughput, customer satisfaction, flexibility and quality.

Secondly, there is need to look into the development of a suitable set of measures which will be used for measuring the performance of the green supply chain. These measures will be based on a given industry as different industries require different supply chain concepts. Therefore, a contingency theory needs to be applied, since different organizations require different measures. This is because environmentally conscious supply chain management involves the proper control of all immediate and eventual effects of processes associated with translating raw materials into final products, with the objective of effectively balancing today's interests with those of future generations. Thus, the measures for this type of supply chain performance measurement will greatly differ from the traditional measures and also differ from one industry to another. This is buttressed by assertions as stated in the ensuing lines; such performance measurement system must 
include measures for the environmental categories as well as the existing operational measures ${ }^{[2]}$. Since some measures cannot be presented in quantitative format because they are uncertain and ambiguous, yet they are important to supply chain performance ${ }^{[12]}$, it is therefore a challenge to measure qualitative measures and to integrate with quantitative measures both traditional and environmental in order to establish the green position of a supply chain.

\section{CONCLUSION}

This study began with an emphasis on the need for an effective and efficient supply chain performance measurement. It went further to highlight the benefits accruable from the use of fuzzy logic operation in supply chain performance measurement. Previous studies using fuzzy logic application in supply chain performance measurement were reviewed and analyzed. Following this, their strengths and limitations were pointed out. Finally, the research culminates with suggestions on applying fuzzy logic operations in measuring the performance of a green or sustainable supply chain (close loop chain). Hopefully, this will give a more comprehensive approach to performance measurement within the supply chain management domain.

\section{ACKNOWLEDGEMENT}

The researchers would like to express their gratitude to the Research Management Center of the University Technology Malaysia, for their support in this study.

\section{REFERENCES}

1. Sabri, E.H. and M. Beamon, 2000. A multiobjective approach to simultaneous strategic and operational planning in supply chain design. Int. J. Manage. Sci., 1: 581-598. DOI: 10.1016/S03050483(99)00080-8

2. Beamon, B.M, 1999. Designing the green supply chain. Logist. Inform. Manage., 12: 332-342. DOI: 10.1108/09576059910284159

3. Vonderembse, M.A., M. Uppal, S.H. Huang and Dismukes, 2006. Designing supply chains: Towards theory development. Int. J. Prod. Econ., 100: 223-238. DOI: 10.1016/j.ijpe.2004.11.014

4. Chan, F.T.S., H.J. Qi, H.K. Chan, H.C.W. Lau and R.W.L. Ip, 2003. A conceptual model of performance measurement for supply chains. Manage. Dec., 41: 635-642. DOI: $10.1108 / 00251740310495568$
5. Lin, C., T.H. Chiu and Y.H. Tseng, 2006. Agility evaluation using fuzzy logic. Int. J. Prod. Econ., 1: 353-368. DOI: 10.1016/j.ijpe.2004.11.013

6. Mentzer, J.T., M.B. Meyers and T.P. Stank, 2007. Handbook of Global Supply Chain Management. Sage Publications Inc., CA., ISBN: 1412918057, pp: 585.

7. Li, S., B. Ragu-Nathan, T.S. Ragu-Nathan and S.S. Rao, 2006. The impact of supply chain management practices on competitive advantage and organizational performance. Omega Int. J. Manage. Sci., 34: 107-124. DOI: 10.1016/j.omega.2004.08.002

8. Chan, F.T.S. and H.J. Qi, 2003. An innovative performance measurement method for supply chain management. Supply Chain Manage. Int. J., 8: 209-223. DOI: $10.1108 / 13598540310484618$

9. Fox, M.S., M. Barbyceanu and R. Teigen, 2000. Agent-oriented supply chain management. Int. J. Flexible Manufactur. Syst., 1: 165-188. DOI: 10.1023/A:1008195614074

10. Wong, P.W. and K.Y. Wong, 2007. Supply chain performance measurement system using DEA modeling. Ind. Manage. Data Syst., 107: 361-381. DOI: $10.1108 / 02635570710734271$

11. Hult, G.T.M., D.J.K. Ketchen and M. Arrelti, 2007. Strategic supply chain management: Improving performance through a culture of competitiveness and knowledge development. Strat. Manage. J., 28: 1035-1052. http://ibc.msu.edu/hult/publications/SMJ07c.pdf

12. Xu, X.X.L., B. Ma and R. Lima, 2007. AHP based supply chain performance measurement system. Proceedings of the Conference on Emerging Technologies and Factory Automation, Sept. 2528, IEEE Xplore, Patras, pp: 1308-1315. DOI: 10.1109/EFTA.2007.4416932

13. Hervani, A.A., M.M. Helms and J. Sarki, 2005. Performance measurement for green supply chain management. Benchmark. Int. J., 12: 330-353. DOI: 10.1108/14635770510609015

14. Childerhouse, P. and D.R. Towill, 2002. Analysis of factors affecting real-world value stream performance. Int. J. Prod. Res., 40: 3499-3518. DOI: $10.1080 / 00207540210152885$

15. Huang, G.Q., J.S.K. Lau and K.L. Mak, 2003. The impact of sharing production information on supply chain dynamics: A review of literature. Int. J. Prod. Res., 41: 1483-1517. www.ingentaconnect.com

16. Gunasekaran, A., C. Patel and R.E. McCaughey, 2004. A framework for supply chain performance measurement. Int. J. Prod. Econ., 87: 333-347. DOI: 10.1016/j.ijpe.2003.08.003 
17. Lai, K., E.W.T. Ngai and T.C.E. Cheng, 2002. Measures for evaluating supply chain performance in transport logistics. Transport. Res. Part E., 38: 439-456. DOI: 10.1016/S1366-5545(02)00019-4

18. Liang, L., F. Feng, W.D. Cook and J. Zhu, 2006. DEA models for supply chain efficiency evaluation. Ann. Operat. Res., 145: 35-49. DOI: 10.1007/s10479-006-0026-7

19. Bhagwat, M. and M.K. Sharma, 2007. Performance measurement of supply chain management: A balanced scorecard approach. Comput. Ind. Eng., 53: 43-62. DOI: 10.1016/j.cie.2007.04.001

20. Neely, A., 2005. The evolution of performance measurement research. Int. J. Operat. Prod. Manage., 1: 1264-1277. DOI: $10.1108 / 01443570510633648$

21. Neely, A., M. Gregory and K. Platts, 2005. Performance measurement system design: A literature review and research agenda. Int. J. Operat. Prod. Manage., 25: 1228-1263. DOI: 10.1108/01443570510633639

22. Kaplan, R.S. and P.D. Norton, 2007. Using the balanced scorecard as a strategic management system. Harvard Bus. Rev., 74: 75-87. http://direct.bl.uk/bld/PlaceOrder.do?UIN=002011 979\&ETOC $=$ RN \& from $=$ searchengine

23. Gunasekaran, A., C. Patel and E. Tirtiroglu, 2001. Performance measures and metrics in a supply chain. Int. J. Operat. Prod. Manage., 21: 71-87. DOI: $10.1108 / 01443570110358468$

24. Bond, T.C., 1999. The role of performance measurement in continuous improvement. Int. J. Operat. Prod. Manage., 19: 1318-334. DOI: 10.1108/01443579910294291

25. Huan, S.H., S.K. Sheoran and G. Wang, 2004. Review and analysis of the Supply Chain Operation Reference (SCOR) model. Supply Chain Manage. Int. J., 9: 23-29. DOI: 10.1108/1359854041051755

26. Chen, Y., L. Liang and F. Yang, 2006. A DEA game model approach to supply chain efficiency. Operat. Res., 145: 5-13. DOI: 10.1007/s10479006-0022-y

27. Baramichai, M., E.W. Zimmers and C.A. Marangos, 2007. Agile supply chain transformation matrix: An integrated tool for creating an agile enterprise. Supply Chain Manage. Int. J., 12: 334-348. DOI: 10.1108/13598540710776917

28. Berrah, L. and V. Chivlle, 2007. Towards an aggregation performance measurement system model in a supply chain context. Comput. Ind., 58: 709-719. DOI: 10.1016/j.compind.2007.05.012
29. Zheng, P. and K.K. Lai, 2008. Research on supply chain dynamic balanced scorecard based on fuzzy evaluation and markov forecast techniques. Syst. Eng. Theor. Pract., 28: 57-64-80. DOI: 10.1111/j.1468-2370.2007.00202.x

30. Chow, G., T.D. Heaver and L.E. Henriksson, 1994. Logistics performance: Definition and measurement. Int. J. Phys. Distribut. Logist. Manage., 24 : $\quad$ 17-28. $\quad$ DOI: 10.1108/09600039410055981

31. Chan, F.T.S. and H.J. Qi, 2002. A fuzzy basis channel-spanning performance measurement method for supply chain management. J. Eng. Manufact., 216: 1155-1167. DOI: $10.1243 / 095440502760272421$

32. Alex, R., 2007. Fuzzy point estimation and its application on fuzzy supply chain analysis. Fuzzy Sets Syst., 158: 1571-587. DOI: 10.1016/j.fss.2007.01.015

33. Zadeh, L.A., 1978. Fuzzy set as a basis for theory of possibility. Fuzzy Sets Syst., 1: 3-28. DOI: 10.1016/0165-0114(78)90029-5

34. Kumar, P.R. and V. Ravi, 2007. Bankruptcy prediction in banks and firms via statistical and intelligent techniques-a review. Eur. J. Operat. Res., 180: 1-28. DOI: 10.1016/j.ejor.2006.08.043

35. Acaroglu, O., L. Ozdemir and B. Asbury, 2008. A fuzzy logic model to predict specific energy requirement for TBM performance prediction. Tunnell. Underground Space Technol., 23: 600-608. DOI: 10.1016/j.tust.2007.11.003

36. Wang, Y. and D. Bai, 2006. Advanced Fuzzy Logic Technologies in Industrial Applications. 1st Edn., Springer, London, ISBN: -10: 1846284686 , pp: 334.

37. Jain, V., M.K. Tiwari and F.T.S. Chan, 2004. Evaluation of supplier performance using an evolutionary fuzzy based approach. J. Manufactur. Technol. Manage., 1: 735-744. DOI: 10.1108/17410380410565320

38. Ganesh, M., 2006. Introduction to Fuzzy Sets and Fuzzy Logic. Prentice-Hall, New Delhi, ISBN: 81203-2861-2, pp: 256.

39. Yeh, Y., H.C. Cheng and M.L. Chi, 2007. A modified two-tuple FLC model for evaluating the performance of SCM: By the six sigma DMAIC process. Applied Soft Comput., 7: 1027-1034. DOI: $10.1016 /$ j.asoc.2006.06.008

40. Zheng, P. and K.K. Lai, 2008. Agent and multiagent systems: Technologies and applications. Lecture Notes Comput. Sci., 4953: 312-322. DOI: 10.1007/978-3-540-78582-_32. 
41. Kanda, A. and S.G. Deshmukh, 2007. Coordination in supply chains: An evaluation using fuzzy logic. Prod. Plann. Control, 1: 420-435. DOI: 10.1080/09537280701430994

42. Rajkumar, O. and R.P. Kumar, 2004. Performance measurement and evaluation of suppliers in supply chain: An evolutionary fuzzy-based approach. J. Manufactur. Technol. Manage., 1: 723-734. DOI: 10.1108/17410380410565311

43. Chan, D.K.C., K. Yung And A.W.H. Ip, 2002. Application of fuzzy set to process performance. Integrat. Manufactur. Syst., 13: 237-246. DOI: $10.1108 / 09576060210426930$

44. Lazarevic and Wong, 2000. Fuzzy control model in the hospitality industry. Int. J. Agile Manage. Syst., 2: 156-162. DOI: 10.1108/14654650010337195

45. Solvang, W.D., E. Roman, Z. Deng and B. Slovang, 2006. A framework for holistic greening of value chains. Knowl. Enterprise Intel. Strateg. Prod. Des. Manufactur. Manage, 207: 350-355. DOI: 10.1007/0-387-34403-9_48

46. Zhu, Q. and J. Sarki, 2006. An inter-sectoral comparison of green supply chain management in china: Drivers and practices. J. Clean. Prod., 14: 472-486. DOI: 10.1016/j.jclepro.2005.01.003
47. Rao, P. and D. Holt, 2005, Do green supply chains lead to competitiveness and economic performance? Int. J. Operat. Prod. Manage., 25: 898-916. DOI: 10.1108/01443570510613956

48. Tsoulfas, G.T. and C.P. Pappis, 2008. A model for supply chains environmental performance analysis and decision making. J. Clean. Prod., 1: 1-11. DOI: 10.1016/j.jclepro.2008.04.018

49. Hoek, R.I. van Hoek, 1999. From reversed logistics to green supply chains. Supply Chain Manage., 4: 129-134. DOI: $10.1108 / 13598549910279576$

50. Rao, P., O. Castillo, P.S. Intal and A. Sajid, 2006. Environmental indicators for small and medium enterprises in the Philippines: An empirical research. J. Clean. Prod., 14: 505-515. DOI: 10.1016/j.jclepro.2005.03.016

51. Vachon, S. and R.D. Klassen, 2008. Environmental management and manufacturing performance: The role of collaboration in the supply chain. Int. J. Prod. Econ., 111: 299-315. DOI: 10.1016/j.ijpe.2006.11.030 